\title{
Building a Strong Corporate Ethical Identity: KEY FINDINGS FROM SUPPLIERS
}

\author{
Nicola Kleyn \\ Russell Abratt \\ Kerry Chipp \\ Michael Goldman
}

\begin{abstract}
The building of Corporate Ethical Identity, a process referred to as "ethicalization," is an important strategic imperative and represents an integral part of a firm's attempts to build a strong corporate identity across its various stakeholders. This article focuses on ethicalization at SAB Ltd (South Africa's leading producer and distributor of alcoholic and non-alcoholic beverages, and one of the nation's largest manufacturing firms) and the impact of its efforts on supplier perceptions. Leaders and managers must consider six factors that drive the formation of ethical identity across an organization's stakeholders: trusted relationships; organizational citizenship; development and enforcement of ethical policy; procurement contracting; provision of information; and procurement administration. (Keywords: Corporate social responsibility, Corporate image, Ethics)
\end{abstract}

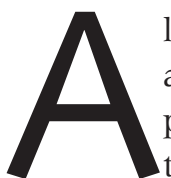

lthough many image and identity studies have focused on customer and employee stakeholders, very little attention has been paid to suppliers as a stakeholder group. This is surprising given the dependencies that organizations have on suppliers for their contribution to product and service quality, cost management, the building of brand equity, and risk management. Consumers and other stakeholders expect a company to act in an ethical manner and it is reasonable to assume that most companies, in time, will be part of a supply chain that experiences a significant violation of ethics. Mattel did not paint its toys with lead paint; Del Monte did not choose poisonous wheat gluten for its pet food; Toshiba did not build flammable batteries in its laptops; and Dole did not put E-coli bacteria in its pre-packaged salads. Toyota's recall of some 10,000 vehicles for "sticky pedals" during 2009 and 2010 was due in part to a breakdown in the buyer-supplier quality relationship, a capability that had previously helped Toyota become the world's largest vehicle manufacturer. ${ }^{1}$ In these examples, suppliers were responsible for these problems, but building an ethical supply chain also requires buyers to consider their ethical behavior vis-à-vis their suppliers. Although ethical transgressions on the part of customers receive far less publicity, the focus on customer ethics is growing. Financial services companies are increasingly expected, ${ }^{2}$ and in certain cases regulated, ${ }^{3}$ to avoid complicity in corruption. In 2006, British 
Nicola Kleyn is a Senior Lecturer in Marketing at the University of Pretoria's Gordon Institute of Business Science in Johannesburg, South Africa.

Russell Abratt is a Professor of Marketing at the Huizenga Business School at Nova Southeastern University as well as a part-time Professor of Marketing in the Wits Business School, University of the Witwatersrand, Johannesburg.

Kerry Chipp is a Senior Lecturer in Research Methodology at the University of Pretoria's Gordon Institute of Business Science in Johannesburg, South Africa.

Michael M. Goldman is a Senior Lecturer in Marketing at the University of Pretoria's Gordon Institute of Business Science in Johannesburg, South Africa.

supermarket chain Tesco yielded to pressure from supplier Tyrrells Crisps to stop supplying grey market products. ${ }^{4}$ As organizations increasingly deepen their partnerships with suppliers, they need to concern themselves not only with the ethical behavior on the part of suppliers, but also with how suppliers view their organizations as well. Positive stakeholder perceptions of an organization's ethical identity has been shown to lead to enhanced stakeholder satisfaction and positively influenced financial performance. ${ }^{5}$

Corporate Identity is the signature that runs through the core of all a corporation does and communicates. ${ }^{6}$ At first, the concept was used by identity and image consultants as well as advertising agencies to develop corporate logos and related graphics. Today, it is used more broadly to encompass the total picture of the way organizations present themselves to different stakeholder groups. Logos and symbols are important, but ultimately, how organizations manage and communicate their behaviors matters more. Recent criticisms of BP after its recent oil spill in the Gulf of Mexico have focused not only on what the company did, but also on its poor communications with stakeholders. ${ }^{7}$

Organizations seeking to build a consistent image and reputation must align many types of identities, one of which is conceived identity, that is, the collective stakeholder images of the organization. ${ }^{8}$ Every stakeholder develops a picture of the organization, driven in part by perceptions of ethical conduct on the part of the corporation. Organizations thus cannot focus only on the management of ethical conduct inside the organization, but must also ensure that they understand how their stakeholders build perceptions of their ethical corporate identity before seeking to align conceived identity with actual identity. ${ }^{9}$

In this study, we explore the ethical perceptions of suppliers to the South African subsidiary of SABMiller plc, South African Breweries Ltd (SAB) and use our findings to derive a model to manage the conceived ethical identity of this, and perhaps other, important stakeholder groups. We begin by investigating the themes of corporate identity management and the role of corporate marketing before examining conceived ethical identity from a general and a supplier perspective, and concluding by discussing SAB's approach to building ethical identity and the findings of our study of their suppliers.

\section{Corporate Identity}

Corporate identity is defined as the values and ethos of an organization that reflects the foundations around which the corporate brand is built. ${ }^{10}$ To help facilitate corporate integrity and better align what a company says and does, employees are frequently regarded as ambassadors underpinning their organization's identity and image, and they are expected to uphold and display their organization's social 
and ethical values. ${ }^{11}$ Balmer and Soenen ${ }^{12}$ and subsequently Balmer and Greyser ${ }^{13}$ developed a conceptual model termed the ACID test. The model synthesizes all the dimensions of identity and is a useful tool for practitioners to identify and avoid potentially harmful identity misalignments in practice. This model highlights six types of identity that are thought to be central and should be aligned to create a competitive advantage for an organization. These six types of identity are the actual (what we really are), communicated (what we say we are), conceived (what we are seen to be), covenanted (what the brand stands for), ideal (what we ought to be), and desired (what we wish to be) identities.

The ACID test framework is a useful tool for managers wanting to measure corporate identity and corporate branding. In the aftermath of BP's merger with the U.S.-based oil company Amoco in 1998, applying the ACID test revealed that the newly merged company's brand positioning was potentially perilous. This was because the corporation's choice to select a brand promise and communications to emphasize its green credentials did not take into account the organization's current reality. ${ }^{14}$ In another study using the ACID test in the financial services sector, gaps were found between lower level employees' perceptions of the actual identity and the ideal identity as desired by management within a major financial institution. ${ }^{15}$ The ACID test has also been applied to the branding of cities. A study of the city of Bradford in the UK highlighted the importance for cities of developing a comprehensive Desired Identity to meet the aspirations of different communities, and ensuring that the Communicated Identity matches the Actual Identity. ${ }^{16}$

Both organizational leaders and employees play an important role in building and communicating corporate identity. The role of organizational leadership is to ensure that there is dynamic congruence rather than perfect alignment among the six identity types. Leaders' influences on ethical practices lie at the heart of authentic leadership, which emphasizes the importance of reconciling the context in which the firm operates with a strong awareness of moral values and perspectives. ${ }^{17}$ Authentic leaders exhibit a higher moral capacity to judge dilemmas from different angles and are able to take into consideration different stakeholder needs. ${ }^{18}$ Much of the existing literature relating to the management of an organization's identity and corporate brand focuses on the importance of creating consistent aligned employee behavior with the corporate brand promise. ${ }^{19}$ Corporate leaders frequently attempt to communicate corporate promises to their various stakeholders about the behavior expected from their employees including the ethical credentials of staff. ${ }^{20}$ In order to align conceived, actual and communicated identity, employees need to understand their role as organizational brand ambassadors and should uphold their organization's values.

\section{The Role of Corporate Marketing in Guiding Corporate Identity}

Although the CEO is ultimately accountable for an organization's identity and reputation, the management of corporate identity, corporate communications, corporate branding, corporate reputation, corporate image, and corporate public relations is increasingly being guided by the adoption of a corporate marketing perspective. ${ }^{21}$ Corporate marketing is defined by Balmer as follows: "Corporate marketing is a customer, stakeholder, societal and CSR/ethical focused philosophy 
enacted via an organizational-wide orientation and culture." ${ }^{22}$ This approach emphasizes the importance of adopting a coordinated approach to align an organization's corporate identity and corporate brand and to foster multi-lateral stakeholder/ societal relationships with the organization to all-round advantage. In its role as custodian of corporate identity, corporate marketing also needs to focus on guiding an organization's ethical identity.

\section{Conceived Ethical Identity}

Back in 2001, Gray and Balmer coined the phrase "ethical identity" and suggested that an ethical posture in combination with a loyal corporate brand community of customers can enhance corporate value. The building of an ethical identity cannot be achieved by simply stating and then executing against ethical values and principles in a corporate mission statement or a code of ethics. Rather, corporations can be identified as being relatively more or less ethical by evaluating the extent to which they embrace social connectedness, openness, critical reflexivity, and responsiveness. ${ }^{23}$ The ethical dimension of a corporation's identity or "corporate ethical identity" (CEI) may be defined as "the set of behaviors, communications, and stances that are representative of an organization's ethical attitudes and beliefs" and includes its ethical values, behaviors, and communications on ethical commitments, all of which may enhance corporate performance. ${ }^{24}$ Ethical identity is embedded when firms take decisive action to behave ethically and to communicate their ethical stance. ${ }^{25}$ For example, in 2009, the World Bank publicized the names of companies that were barred from receiving direct contracts under the Bank Group's corporate procurement program for "providing improper benefits to Bank staff."26

Firms seeking to develop their ethical corporate identity need to give due regard and diligence to their institution's actual identity and to ensure that this is genuinely underpinned by ethical precepts and that communication, perception, brand positioning, and corporate reputation are meaningful aligned. ${ }^{27}$ The editors of a special issue of the Journal of Business Ethics on ethical identity note the importance of four ethicalization themes: foundations, triggers, and motives; management; action and communication; and image and stakeholder perception.

The first theme concerns the motivations and/or triggers that cause an organization to adopt an ethical ethos and to emphasize the corporation's social responsiveness. As organizations increasingly witness their peers enduring crises of ethics, societal stakeholders are increasingly questioning the ethical stance of organizations. This demands that organizations engage in ethical introspection and consideration of their current and ideal corporate ethics.

The second aspect of ethicalization focuses upon the management of ethical identity. Once corporations have decided to pursue greater social responsiveness, then they must adopt change by establishing goals, policies, and procedures; delegating tasks and responsibilities; and installing monitoring and review methods. A study of corporate ethical practices in the 1990s showed that although there was a high degree of adaptation of corporate ethical policies (including codes of ethics), there was a variety in the extent to which these policies were implemented by various supporting structures and managerial activities. Firms differed substantially in their 
efforts to see that these policies and codes are put into practice by organizational members. $^{28}$

The third aspect of ethicalization focuses on the relationship between communication and demonstrated action related to corporate social responsibility (CSR). CSR forms part of the larger construct of corporate citizenship that may be described as actions by corporations that are intended, at least in part, to create benefits for society as a whole and not just for the companies and their shareholders. The concept of corporate citizenship encompasses corporate social responsibility, corporate sustainability, corporate societal marketing, cause marketing, cause-related marketing, green marketing, corporate social marketing, strategic philanthropy, and similar terms used to embody the efforts of companies to serve society at-large. ${ }^{29}$

The fourth aspect of ethicalization thus considers the relevance of customer and other stakeholder perceptions. Different stakeholder groups may have different concerns and images of the organization and its ethics, and these need to be appreciated and managed.

\section{Suppliers and Ethical Identity}

The growing complexity of the supplier environment coupled with the boundary spanning role played by supply managers has given rise to a number of complex ethical dilemmas. ${ }^{30}$ Although a number of studies have emphasized the importance of investigating and managing the ethics of supplier organizations, relatively little attention has been paid to the corresponding importance of understanding supplier perceptions of the ethics of the buying organization. Two dimensions underpin suppliers' conceived ethical identity of a buying organization. ${ }^{31}$ The first is high ethical standards. Elements that may be included here are: the existence and adherence to a code of ethics; legal and moral principles; respect for the confidentiality of suppliers' information and products; product quality; justice with respect to bribery; nepotism; and the politeness of staff. Holding a conceived ethical identity that is associated with high ethical standards contributes to identity building by clearly and unambiguously establishing who the organization is and what it stands for in the ethical domain.

The second dimension of ethical identity focuses on candid relationships. Elements that may lead to good relationships include: speedy resolution of problems; respect for the partner; transparency in its dealings, which include information sharing; clear communications; and fair, but firm negotiations. The association between conceived ethical identity and reputation was investigated in a study of purchasing managers that found that higher levels of ethical responsibility on the part of supplier managers had a significant positive impact on their organization. ${ }^{32}$ The study found that owing to the high visibility of buyer-supplier transactions, a supply management department displaying a high level of ethical responsibility will enjoy higher status both within its company and across external stakeholder groups.

Corporate marketers seeking to build strong, aligned corporate identities therefore need to ensure that they consider the ethical dimension of corporate identity. Suppliers represent an important stakeholder group that practitioners need to understand in order to develop relevant ethical standards and build candid relationships. 


\section{South African Breweries}

Founded in 1895, the South African Breweries Ltd. (SAB) is the South African subsidiary and historical birthplace of SABMiller plc, one of the world's largest brewers by volume with more than 200 brands and brewing interests and distribution agreements in over 60 countries across six continents. SAB is the second largest listed company on the Johannesburg Stock Exchange (JSE), South Africa's leading producer and distributor of alcoholic and non-alcoholic beverages, and one of the nation's largest manufacturing firms.

$\mathrm{SAB}$ is significant for this study as it is not only a leading company in South Africa, but also a major player in the world beer market. It has a long history of corporate social responsibility and ethical behavior. It has won the award for being the "Most Admired Company in South Africa" for 2005, 2009, and 2010. ${ }^{33}$ SAB executives emphasize the importance of ethics in their corporate values. They state that:

- Our reputation is indivisible

- Our reputation relies on the actions and statements of every employee

- We build our reputation for the long term

- We are fair and ethical in all our dealings

- We benefit the local communities in which we operate ${ }^{34}$

As part of their efforts to manage ethical identity across stakeholders, SAB commissioned a study to determine how suppliers conceive their ethical identity. The organization sought to deepen its understanding of the factors that underlie supplier perceptions of ethical identity in order to build their ethical identity with this important stakeholder group.

\section{Methodology}

A case study approach for a single organization was selected, as it allowed for the study of ethical identity in its natural setting. A case study approach provides an empirical inquiry for the context of real life where the boundaries are not clearly evident and in which multiple sources of evidence are used. ${ }^{35}$ Previously published research on organizational identity has endorsed the utility of single case studies when investigating contemporary and previously unexplored phenomena. ${ }^{36}$ A survey was the primary mechanism used to gather data from suppliers. In addition to gathering demographic information about respondents, the survey sought their responses to 36 statements with ethical content; examples included "Everybody is given an equal opportunity to submit proposals for contracts" and "SAB staff members who take bribes face penalties." Additional details of the research design employed are provided in appendix A.

\section{Findings}

A total of 431 supplier representatives responded to the survey. Table 1 summarizes the demographic profile of respondents. 
TAB LE I. Respondent Profile

\begin{tabular}{|c|c|c|c|c|c|}
\hline Age & No. & $\%$ & Position & No. & $\%$ \\
\hline Under 25 & 5 & । & Director/Board member & 115 & 27 \\
\hline $25-34$ & 56 & 13 & General Manager & 54 & 12 \\
\hline $34-49$ & 235 & 55 & Owner/Partner & 26 & 6 \\
\hline Over 49 & 135 & 31 & Functional Expert & 127 & 29 \\
\hline Sex & & & Admin/Clerical & 33 & 8 \\
\hline Male & 104 & 24 & Other & 76 & 18 \\
\hline Female & 327 & 76 & & & \\
\hline $\begin{array}{l}\text { Length of Interaction } \\
\text { with SAB }\end{array}$ & & & $\begin{array}{l}\text { Materials/Services } \\
\text { Supplied }\end{array}$ & & \\
\hline Less than I year & 17 & 4 & Brewing & 56 & 13 \\
\hline $1-3$ years & 68 & 16 & Packaging & 189 & 44 \\
\hline More than 3 years & 346 & 80 & Freight \& Logistics & 24 & 5 \\
\hline Seen Code of Ethics & & & Plant and Capital Equip & 23 & 5 \\
\hline Yes & 235 & 55 & $\mathrm{MRO}$ & | | & 3 \\
\hline No & 196 & 45 & General Supplies & 128 & 30 \\
\hline
\end{tabular}

The typical supplier was female, aged 35-49, a director/board member or sales manager/consultant. Most had three or more years of interaction with SAB. They were located mainly in the Gauteng province, the province that houses the cities of Johannesburg and Pretoria.

In order to identify any underlying dimensions of ethical behavior, the responses to the 36 statements were subject to factor analysis. Our findings indicate that ethical identity is underpinned by six dimensions. These are shown in Figure 1.

\section{Dimensions of Ethical Behavior}

\section{Dimension 1: Trusted Relationships}

Building Supplier Trust is Essential

All of the statements reflect the dimension that suppliers require a trusted relationship. Statements show that suppliers consider SAB's performance across the typical phases of buyer-supplier interaction including price negotiation, contracting, product and service delivery, and supporting administration. Despite its industry dominance, SAB's lack of abuse, its transparency, and the respect it paid to its suppliers has resulted in a relatively positive rating. This finding is in line with the $\mathrm{SAB}$ value statement, which states that: "We build lasting relationships, based on trust."37

These positive ratings by suppliers show that SAB values the concept of relationship management. Typically, suppliers interact with employees who are at different levels and play different roles in the buying organization. The consistently high ratings are indicative of how SAB employees all contribute to building the supplier relationships by adhering to the company's mission and values. As the sales directors, managers, and representatives of supplier organizations interact with procurement managers and administrative support personnel, the corporate culture and values as set by the leadership of the company are being adhered to. 
FIGURE I. Conceived Ethical Identity

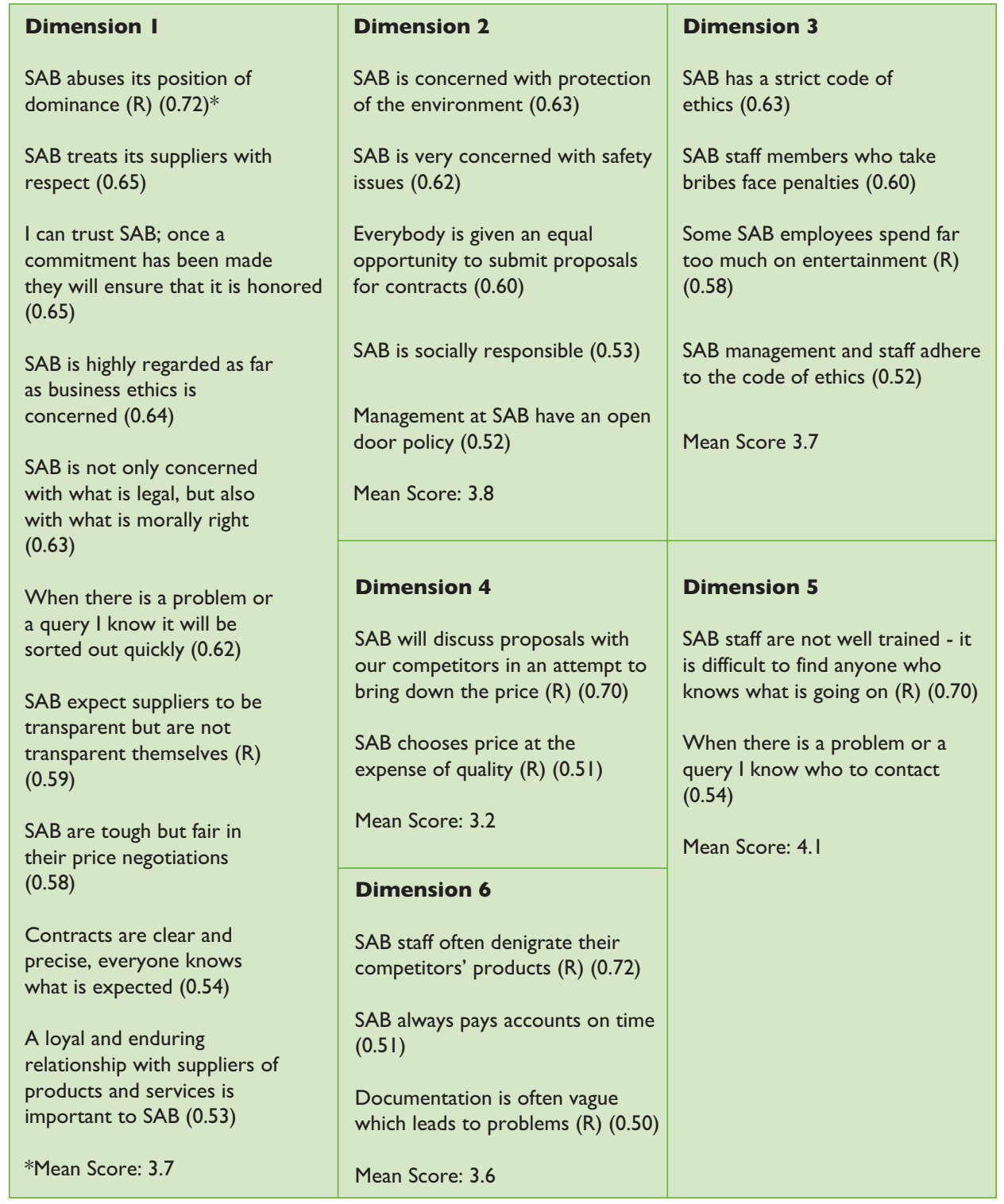

*scale: I=strongly disagree, 5 = strongly agree; $\mathrm{R}$ : indicates that this item is reverse scaled; factor loadings are indicated after each statement.

\section{Dimension 2: Organizational Citizenship}

The Tone Set by the Executive Leadership Matters

Statements associated with this dimension all relate to a common theme of responsible citizenship by the executive leaders of SAB. This dimension addresses a range of corporate policy issues, including SAB's concerns with environmental 
protection, safety issues, corporate social responsibility, the provision of equal opportunities, and safety issues. $\mathrm{SAB}$ has ten priorities in this regard: discouraging irresponsible drinking; making more beer using less water; reducing SAB's energy and carbon footprint; packaging reuse and recycling; working towards zero-waste operations; encouraging enterprise development in SAB's value chains; benefiting communities; contributing to the reduction of HIV/AIDS; respecting human rights; and transparency and ethics. ${ }^{38}$

The importance of management accessibility shows that this dimension goes beyond mere policy setting and also includes the extent to which senior leadership are willing to engage with their stakeholders around these issues. The emergence of this dimension shows that building an ethical identity with suppliers is not purely a functional issue; it depends on the action and tone set by organizational leaders.

\section{Dimension 3: Development and Enforcement of Ethical Policy} Ethical Values and Behaviors must be Reinforced

All statements associated with Dimension 3 are directly associated with issues concerning the development and enforcement of ethical codes. When evaluating the enforcement of ethical behavior, respondents considered the existence of the code, adherence to the code (both generally and specifically around issues of entertainment and awarding contracts to family and friends), and the implications of transgressing the code, particularly in the case of employees who pay bribes.

Ethics is an important aspect of SAB's corporate identity and their code of ethics explicitly spells out the firm's ethical stance and communicates this to every employee in the company. The results of this study indicate that most of the suppliers are aware of the existence of this code and feel positive that the members of the procurement department adhere strictly to the code. The existence of this dimension underscores the importance of reinforcing the ethical values of management and employees through the development and enforcement of ethical codes. An $\mathrm{SAB}$ document addressing its commitment to stakeholders states: "The company believes external stakeholders should be able to access information easily to enable them to assess the company's performance against stated values and to make informed judgments about the business. Transparency and open reporting on its activities are important to SAB because consumers want to know that its beers and soft drinks are of consistently high quality; its employees want to work for a company that they know is honest and committed to behaving responsibly; its suppliers and business partners want a fair relationship; and the communities in which SAB works want to know that it operates in a way that will not damage their environment or quality of life." 39

\section{Dimension 4: Procurement Contracting}

Procurement Managers need to be Fair and Confidential in their Dealings with Suppliers

The two statements loading onto this dimension emphasize the importance of ethical behavior at a senior level within the procurement function. Both items loading onto the factor sit at the heart of responsible procurement practice; namely, that $\mathrm{SAB}$ will not discuss proposals with their competitors in an attempt to bring down the 
price and that SAB does not choose price at the expense of quality. SAB's suppliers believe that the procurement managers are fair and keep matters between suppliers confidential, and they do not play off one supplier's offering against another in order to obtain more favorable terms for SAB.

\section{Dimension 5: Provision of Information}

Suppliers need Clearly Identifiable Competent Employees to Provide Information to Resolve Problems or Queries

The fifth dimension also involves employees in the procurement functions but focuses on the importance of providing information to suppliers. Suppliers valued well-trained employees and knowing who to contact with a problem or query. Where the previous dimension emphasized the importance of systems and processes, this dimension also stresses the importance of the human face of the procurement function.

The results confirm that an organization's ethical identity is formed at all levels of the firm. To perform well as an ethical organization, the leaders, middlelevel managers, and operational-level employees must display the highest level of ethical conduct. The findings of our study reflect very positively on all the people who work at SAB. Normally, a shared organizational identity, and especially an ethical organizational identity, may be perceived differently by the different levels in a firm's hierarchy. At SAB, leaders at board level that formulate the mission and corporate vision, and that play a major role in strategy formulation, have harmonized with middle management who must implement through aligned organizational processes, and they encourage operational employees at the bottom end of the hierarchy to embrace an ethical culture. Our findings suggest that there is strong alignment of the firm's ethical identity across all levels of the organizational hierarchy.

\section{Dimension 6: Procurement Administration}

Getting the Paperwork Done Accurately and on Time Drives Ethical Perceptions

The emergence of a final dimension that focuses on administrative efficiency shows the importance of implementing policies and procedures that enable administrative employees to interact efficiently and effectively with suppliers. The statements that loaded on this dimension stressed the importance of: not denigrating competitors' products; paying accounts on time; and ensuring that documentation is precise. Although administrative efficiency is seldom viewed as an ethical issue, weak administrative systems rob suppliers of time, energy, and (in the case of late payments) revenue as well.

\section{Implications}

Corporate ethical identity requires alignment of ethical principles between the leadership of the organization and its employees. Managers building ethical identity may benefit from asking the following four questions: How important is ethical identity to us? How do we communicate our ethical identity? How is our ethical identity conceived by others? How can we embed our ethical identity across the 
organization ${ }^{40}$ This approach incorporates moral and ethical principles in an organization's decision making and takes all stakeholder groups into account.

Embracing positive ethical values makes an important contribution to ongoing supplier/buyer relationships. The high ratings awarded by SAB's suppliers indicated that the conceived ethical identity of this stakeholder group is strong and positive. Analysis of the factors driving ethical perceptions reveals that the leaders, procurement managers, and administrative support staff all play a role in shaping the identity of SAB. The alignment of SAB's ethical attitudes, as reflected in its mission statement and ethical code, and the behaviors of managers and employees across the organization are key to the building of a strong positive ethical identity. What unites SAB's leadership and its employees are its ethical values, which it strongly emphasizes, and this lies at the core of its ethical conduct. Our findings suggest that SAB is a good example of a firm that can be identified as being ethical by their social connectedness, openness, critical reflexivity, and responsiveness. The fact that they conduct surveys of this nature shows that they not only understand the concept of corporate ethical identity, it is deeply embedded in their value system and they practice it. This supplier satisfaction, at least on the ethical dimension, suggests that suppliers will continue to provide their products and services to SAB in the future for mutual benefit.

These findings have important implications for any organization seeking to build an ethical identity across stakeholders.

\section{Building a Strong Ethical Identity}

Firms seeking to build trusted relationships with any stakeholder group need to focus on building a strong ethical identity. Stakeholder theory posits that the behavior of an organization can be understood and predicted based on: the nature of diverse stakeholders; the norms defining right and wrong adopted by these stakeholders; and stakeholders' relative influence on organizational decisions. ${ }^{41}$ CSR has a positive effect on behaviors on the job like job-related effort, and it can provide stakeholders with numerous types of benefits. ${ }^{42}$ The process of becoming a good corporate citizen involves engaging honestly in dialogues with stakeholders, in our case suppliers, by having conversations in which core values and assumptions are openly articulated, and where mutual concerns and issues can be discussed in a non-threatening way. ${ }^{43}$ The six dimensions that emerged as key findings from the study have been synthesized into two key areas of managerial focus and are shown in Figure Two.

\section{Develop the Ethical Core}

Management must Determine what being Ethical Means to the Company

Developing an ethical identity cannot begin without acknowledgement on the part of corporate leadership of the importance of building trusted relationships with all stakeholders. The characteristics of social connectedness, openness, critical reflexivity, and responsiveness should be conveyed and lived by the leadership of the organization-including the chairman, chief executive officer, and the board of directors-in both oral and written communications. Ethical values of the firm's 
FIGURE 2. Building Ethical Identity

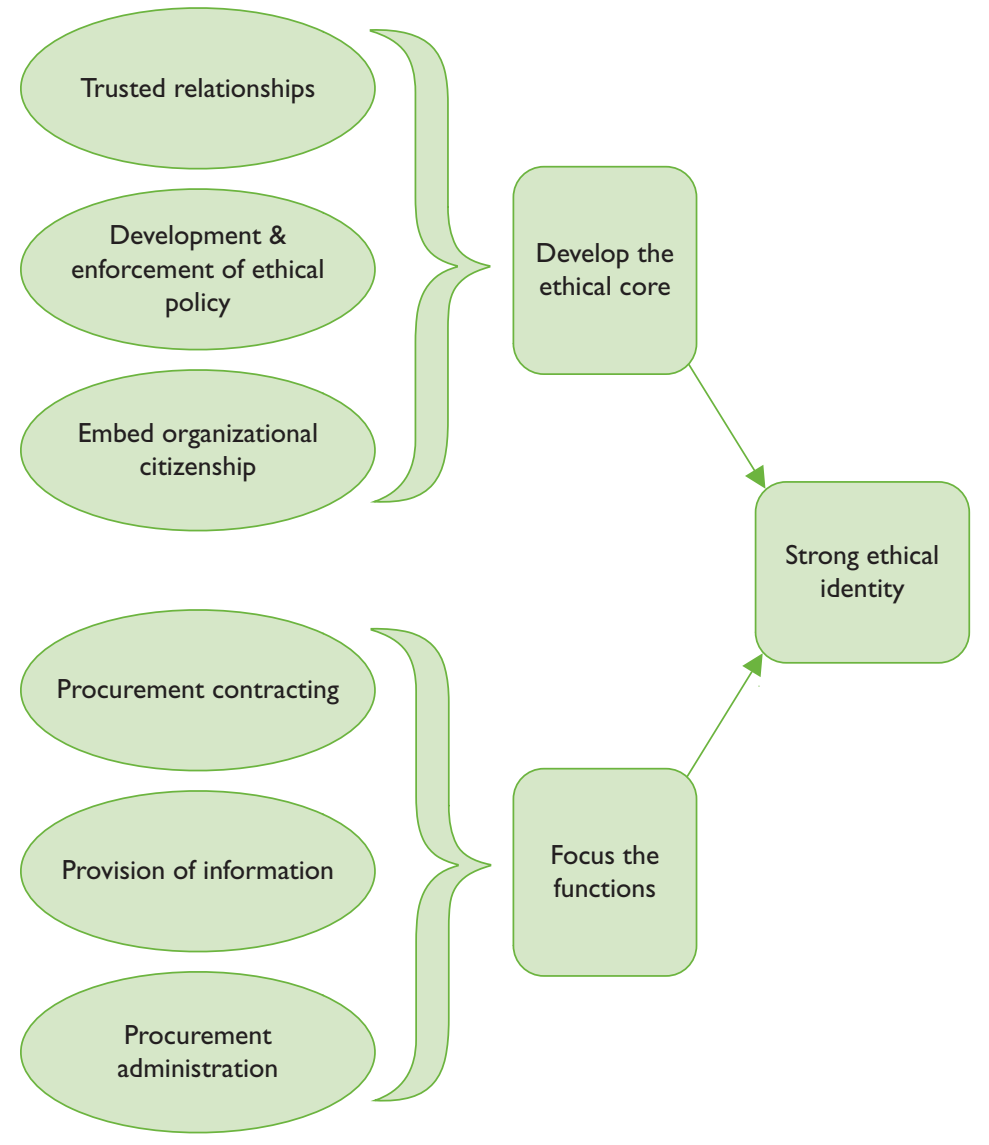

leadership need to be reflected in the firm's mission statements and will drive the development of a code of ethics. The organization's leadership then plays a critical role in demonstrating the importance of ethics, what it means to be ethical, and how ethical behavior will be enforced throughout all levels of the organization to obtain buy-in from organizational citizens. Embedding these ethical values is not achieved through communication alone, but also by the behaviors of the leadership and their accessibility and availability to employees and other stakeholders to address issues of ethical misconduct. It is only through agreeing, communicating, and living ethical values that they become an integral component of the corporate culture.

\section{Corporate Citizenship cannot be Separated from Ethics}

While the ethical code governs the conduct of employees, corporate citizenship governs that of the firm relative to society and the environment. Once organizational leadership have agreed on the environmental and societal role they seek to 
play, executive management needs to enable corporate citizenship by approving the creation of structures, systems, processes, and budgets required for the firm to make an active contribution to societal and environmental improvement. Leadership also needs to communicate the importance of corporate citizenship to all stakeholders, particularly employees who need to move beyond being passive observers of corporate citizenship activities, to playing the active role that citizenship requires. For example, SAB is involved in sports sponsorships, including the national soccer, rugby, and cricket teams, as well as the major domestic competitions in these sports.

\section{Focus the Functions}

Management needs to also Focus on Stakeholder Specific Issues that Typically Lie in the Domain of Organizational Functions

Although the development of an ethical core and the establishment of corporate citizenship build the foundations of ethical identity, firms need to also focus on stakeholder specific issues that typically lie in the domain of organizational functions. The findings of this study show, for example, that in the case of suppliers, contracting, administration, and the provision of information are important factors driving supplier perceptions of ethical identity in the procurement function in the organization. Functional management (that is, the procurement department) plays an integral role in this process of ethicalization by communicating ethical policy and decisions taken by the organization's executive leadership, aligning the buying function to these and to supplier requirements for ethical conduct, and reinforcing a culture of ethics through behavior that conforms to the mission, code of ethics, and functional standards.

Stakeholder requirements need to be identified by engaging in research to build a deep understanding of how each stakeholder group evaluates ethical conduct. These findings need to be considered when designing corporate systems and processes. Employee sensitization and training on the organizational code of ethics, organizational efforts to build corporate citizenship, and the functional response to stakeholder specific requirements are also required to build ethical identity. "People matter" is one of SAB's key values. SAB pioneered an "affirmative action" program in the mid-1970s to alleviate historical inequities and disadvantages experienced by many of its employees.

Over time, functional management also needs to ensure that it engages in regular stakeholder communication to convey the steps that have been taken to promote ethical behavior. Periodic measurement of stakeholder perceptions of ethical identity-followed by feedback to both employees and the stakeholder group and by corrective action where required-is an integral component of the management of conceived ethical identity.

It is only when organizations have strong, positive ethical identities that they can build trusted relationships across stakeholder groups. The process of ethicalization requires a focused effort on the part of organizational leadership to build an ethical core, to identify and execute its role as an organizational citizen, and to adapt behavior at a functional level to meet stakeholder requirements for ethical conduct. 
APPENDIX A

\section{Overview of Methodology}

A survey was undertaken among the suppliers of SAB. The development of scale items resulted from focus group discussions with groups of suppliers to determine how they evaluated the ethical identity of organizations to which they sold. This resulted in the development of a number of statements about SAB which respondents were asked to rate using a five-point Likert scale with the enumeration ranging from strongly agree to strongly disagree. Approximately one-third of the statements were phrased in the negative so as to ensure that the full range of the scale was utilized. The scale was pre-tested prior to this survey and was purified to enhance reliability and validity. Thirty-eight statements were selected to form the main body of the questionnaire, which was supplemented with two questions pertaining to the overall perceptions of ethical behavior of SAB, and two open-ended questions where respondents could give examples of good and poor ethical behavior by SAB employees. The first of the closed-ended questions required respondents to rate SAB's ethical standards on a 10-point numeric scale where 1 represented poor and 10 excellent. Respondents were then asked to rate SAB's ethical standards relative to other customers on a five-point verbal scale ranging from much better to much worse.

Although SAB maintains a detailed supplier list with a primary point of contact for all of its supplier organizations, it was agreed that ideally all individuals in supplier organizations who have any interaction with SAB should be included in the survey. Saturation surveying was used to expand the sampling frame. The individuals on the database were contacted during January 2010 to request them to nominate additional individuals within the organization who had regular contact with SAB. Respondents were requested to complete an online survey by clicking on a link to the survey, which was housed on a well-known business school's website. Individuals were guaranteed anonymity. A mixture of open-ended and closedended questions was used to ascertain respondent demographics and opinions.

Before using a principal factor analysis using Varimax with Kaiser normalization to identify the drivers of ethical identity, Cronbach's alpha was calculated for the scale in its entirety and with each item removed. All measures of $\alpha$ exceeded .935 thus indicating acceptable reliability for scale items. Results of the factor analysis indicated that a six-factor solution was the most appropriate. Kaiser-Mayer-Olkin and Bartlett's tests were performed to assess sampling adequacy and sphericity and scored. Analysis of the results indicated that the former scored an acceptable 0.943 whilst the significance level of the latter was 0.00. All items shown in Figure 1 were extracted by examining the factor loadings and cross-loadings (shown below) and selecting items scoring a factor loading greater or equal to 0.05. Additional details of statistical procedures and results are available from the authors on request.

\section{Notes}

1. See "Toyota swings to profit despite recall woes," CNN Money, May 11, 2010, accessed August 26, 2010, <http://money.cnn.com/2010/05/11/news/companies/toyota_earnings.cnnw/index.htm>; David Grant, "Toyota recall: As firms go global, so do their glitches," The Christian Science Monitor, February 26, 2010, accessed August 18, 2010, http://www.csmonitor.com/Business/2010/0208/ Toyota-recall-As-firms-go-global-so-do-their-glitches. 
2. "British banks warned to investigate corrupt customers more rigorously after watchdog reveals five took millions from corrupt Nigerian governors," Daily Mail Online, October 11, 2010, accessed October 9, 2011, http://www.dailymail.co.uk/new/article-13195666/British-banks-warned-investigatecustomers/.

3. "Foreign Corrupt Practices Act," World-Check, accessed October 9, 2011, http://www.fcpa.us.

4. James Hall, "Tesco backs down from fight over Tyrrell's crips," The Telegraph, September 17, 2006, accessed October 10, 2011, http://www.telegraph.co.uk/finance/2947463/Tesco-backs-downfrom-fight-over-Tyrrells-crisps.html.

5. Pascual Berrone, Jordi Surroca, and Josep A. Tribó, “Corporate Ethical Identity as a Determinant of Firm Performance: A Test of the Mediating Role of Stakeholder Satisfaction," Journal of Business Ethics 76/1 (November 2007): 35-53.

6. John M.T. Balmer, Kyoko Fukukawa, and Edmund R. Gray, “The Nature and Management of Ethical Corporate Identity: A Commentary on Corporate Identity, Corporate Social Responsibility and Ethics," Journal of Business Ethics, 76/1 (November 2007): 7-15.

7. Joel Achenbach and David S. Hilzenrath, "BP's Kent Wells questioned about who had final responsibility in drilling work," Washington Post, August 26, 2010, accessed September 8, 2010 , <www.washingtonpost.com/wp-dyn/content/article/2010/08/26/AR2010082604060.html>.

8. For a detailed discussion of conceived identity refer to John M.T. Balmer, Helen Stuart, and Stephen A. Greyser, "Aligning Identity and Strategy: Corporate Branding at British Airways in the late $20^{\text {th }}$ Century," California Management Review, 51/3 (Spring 2009): 7-23.

9. Balmer, Fukukawa, and Gray, op. cit.

10. John M.T. Balmer and Edmund R. Gray, "Corporate brands: What are they? What of them?" European Journal of Marketing, 37/7-8 (2003): 972-997.

11. Shaun Powell, Wim J.L. Elving, Chris Dodd, and Julia Sloan, "Explicating ethical corporate identity in the financial sector," Corporate Communications: An International Journal, 14/4 (October 2009): 440-455.

12. Balmer and Soenen introduced the ACID test model. John M. T. Balmer and Guillaume B. Soenen, "The Acid Test of Corporate Identity Management ${ }^{\mathrm{TM}}$," Journal of Marketing Management, no. 15/1-3 (January-April 1999): 69-92. The model has been updated twice since then. The newest version of the model can be found in Balmer and Gray (2003), op. cit.

13. John M.T. Balmer and Stephen A. Greyser, "Managing the Multiple Identities of the Corporation," California Management Review, 44/3 (Spring 2002): 72-86.

14. John M.T. Balmer, "The BP Deepwater Horizon debacle and corporate brand exuberance," Journal of Brand Management 18 (2010): 97-104.

15. Powell, Elving, Dodd, and Sloan, op. cit.

16. Myfanwy Trueman, Mary Klemm, and Axele Giroud, "Can a city communicate? Bradford as a corporate brand," Corporate Communications: An International Journal, 9/4 (2004): 317-330.

17. Amy Klemm Verbos, Joseph A. Gerard, Paul R. Forshey, Charles S. Harding, and Janice S. Miller, "The Positive Ethical Organization: Enacting a Living Code of Ethics and Ethical Organizational Identity," Journal of Business Ethics, 76/1 (November 2007): 17-33.

18. Douglas R. May, Adrian Y.L. Chan, Timothy D. Hodges, and Bruce J. Avolio, "Developing the Moral Component of Authentic Leadership," Organizational Dynamics, 32/3 (August 2003): 247-260.

19. Powell, Elving, Dodd, and Sloan, op. cit.

20. Shaun Powell, "The Nexus between ethical corporate marketing, ethical corporate identity and corporate social responsibility: an internal organizational perspective," European Journal of Marketing, 45/9-10 (2011): 1365-1379.

21. John M.T. Balmer and Stephen A. Greyser, Revealing the Corporation: Perspectives on Identity, Image, Reputation, Corporate Branding, and Corporate-level Marketing (London: Routledge, 2003).

22. John M.T. Balmer, "Corporate marketing myopia and the inexorable rise of a corporate marketing logic: perspectives from identity based views of the firm," European Journal of Marketing, 45/9-10 (2011): 1350.

23. Kyoko Fukukawa, John M. T. Balmer, and Edmund R. Gray, "Mapping the Interface Between Corporate Identity, Ethics and Corporate Social Responsibility," Journal of Business Ethics, 76/1 (November 2007): 1-5.

24. Pascual Berrone, Jordi Surroca, and Josep A. Tribó, “Corporate Ethical Identity as a Determinant of Firm Performance: a Test of the Mediating Role of Stakeholder Satisfaction" Journal of Business Ethics, 76/1 (November 2007): 35-53.

25. Ibid. 
26. See "World Bank Listing of Ineligible Firms \& Individuals," The World Bank Group, accessed September 3, 2010 , <http://web.worldbank.org/external/default/main?theSitePK=842668 contentMDK=640698448menuPK=1 16730\&pagePK=64148989\&piPK=64148984>; “World Bank Publishes Procurement Blacklist," Seeking Alpha, accessed September 3, 2010, <http://seekingalpha. com/article/1 14819-world-bank-publishes-procurement-blacklist>.

27. Powell, op. cit.

28. Gary R. Weaver, Linda Klebe Treviño, and Philip L. Cochran, “Corporate Ethics Practices in the Mid-1990's," Journal of Business Ethics, 18/3 (February 1999): 283-294.

29. Steve Hoeffler, Paul N. Bloom, and Kevin Lane Keller, "Understanding Stakeholder Responses to Corporate Citizenship Initiatives: Managerial Guidelines and Research Directions," Journal of Public Policy and Marketing, 29/1 (Spring 2010): 78-88.

30. Reham A. Eltantawy, Gavin L. Fox, and Larry Guinipero, "Supply Management Ethical Responsibility: Reputation and Performance Impacts," Supply Chain Management: An International Journal, 14/2 (March 2009): 99-108.

31. Michael Bendixen and Russell Abratt, "Corporate Identity, Ethics and Reputation in SupplierBuyer Relationships," Journal of Business Ethics, 76/l (November 2007): 69-82.

32. Eltantawy, Fox, and Guinipero, op. cit.

33. "SAB Ltd Corporate Brochure," SAB Limited, accessed June 12, 201 1, <www.sablimited.co.za/ sablimited/action/media/downloadFile?media_fileid=79l>.

34. Ibid.

35. Robert K. Yin, Case Study Research: Design and Methods, $4^{\text {th }}$ ed. (Los Angeles: Sage, 2009).

36. John M. T. Balmer, "Corporate heritage brands and the precepts of corporate heritage brand management: Insights from the British Monarchy on the eve of the royal wedding of Prince William (April 2011) and Queen Elizabeth II's Diamond Jubilee (1952-2012)," Journal of Brand Management, 18/8 (June 2011): 517-544.

37. "Vision and Values," SAB Limited, accessed June 15, 2011, http://www.sablimited.co.za/sablimited/ content/en/sab-vision-and-values.

38. "Sustainable Development," SAB Limited, accessed June 15, 2011, <www.sablimited.co.za/ sablimited/content/en/sustainable-development-listing >.

39. “Committed to Sustainable Development," SAB Limited, accessed June 19, 201 1, <www.sablimited. co.za/sablimited/action/media/downloadFile?media_fileid=778>.

40. Balmer, Fukukawa, and Gray, op. cit.

41. Isabelle Maignon and O.C. Ferrell, "Corporate Social Responsibility and Marketing: An Integrative Framework," Journal of the Academy of Marketing Science, 32/1 (Winter 2004): 3-19.

42. C.B. Bhattacharya, Daniel Karschun, and Sankar Sen, "Strengthening Stakeholder-Company Relationships Through Mutually Beneficial Corporate Social Responsibility Initiatives," Journal of Business Ethics, 85/2 (April 2009): 257-272.

43. Sandra Waddock and Neil Smith, "Relationships: The Real Challenge of Corporate Global Citizenship," Business and Society Review, 105/1 (Spring 2000): 47-62.

California Management Review, Vol. 54, No. 3, pp. 61-76. ISSN 0008-1256, eISSN 2162-8564. () 2012 by The Regents of the University of California. All rights reserved. Request permission to photocopy or reproduce article content at the University of California Press's Rights and Permissions website at http://www.ucpressjournals.com/reprintinfo.asp. DOI: 10.1525/cmr.2012.54.3.61. 